\title{
A Study on the Artistic Features of the Patterns of Xiaoyi Shadow Play
}

\author{
Qiqi Cao ${ }^{1, a}$ \\ ${ }^{1}$ Taiyuan University of Technology, Taiyuan, Shanxi, China \\ a523902170@qq.com
}

Keywords: Xiaoyi shadow play; design style; pattern.

\begin{abstract}
Xiaoyi shadow play is an important tribe of Chinese shadow play. It has typical regional characteristics, which has a rich cultural heritage and a broad mass base. Its origin and development are indissolubly related to traditional culture and drama art, as well as folk paper cutting, painting, puppets, religious murals and other types of art. They interact to gradually develop. The decorative patterns and styles of shadow play are the focus of living art. They reflect the grass-roots people's aesthetic needs, psychological needs and spiritual sustenance, as well as the rich regional culture and folk religious beliefs. Xiaoyi shadow play, with unique styles of decorative patterns and diverse beauty of pattern forms, reflects the aesthetic habits with rich local characteristics, which is the main feature of the patterns of Xiaoyi shadow play. .
\end{abstract}

\section{Introduction}

The art of shadow play has been widely spread in the folk, which is known as "the oldest film in China". It is based on the ancient folk culture and gradually develops in a relatively isolated and self-contained environment, which fully embodies the common people's rich inner world and unique aesthetic pursuit. Xiaoyi shadow play is also known as "light", "shadow play". In ancient times, it is based on the belief of folk art, which often occurs in the countryside activities, such as, praying, sacrificial ceremony, marriage and funeral ceremonies and asking god for help. In addition, shadow play is also adopted in Chinese Spring Festival to heighten the atmosphere and to express the people's satisfaction.

Xiaoyi is located in Donglu, the middle of Lvliang Mountain, Shanxi Province. It is to the west of Fenhe River, to the southwest of Jinzhong basin [1]. Xiaoyi is next to both Lvliang and Fenhe River, which is one of the three centers of Shanxi folk art. Locating in the Yellow River River, Xiaoyi is known as "The Land of Rural Culture" and "The Land of Chinese Opera". It could not be an opera without Xiaoyi shadow play. Xiaoyi shadow play develops in this social environment with profound cultural foundation. [2] In May 20th 2006, with the approval of the State Council, Xiaoyi shadow play was included in the first batch of national intangible cultural heritage. In Shanxi Province, folk paper-cut, temple murals, grotto art, architecture and brick carving, wood carving and some other art forms have been popular since the ancient times, which inspired the art of shadow carving to some extent, especially in its design style, color, pattern design, etc. Mr. Chen Zhifo, an expert of pattern design, points out in his book ABC Patterns that the study of ancient works should not only focus on the history of decorative patterns. We should also research into the principles of the past studies, the relationship between human beings and the patterns, a pattern and the people's life and ideals in that period, the exact conditions in which the pattern is produced. These problems are the most significant and essential. [3] The decorative pattern of shadow play and its design style not only reflects the grass-roots people's aesthetic needs, psychological needs and their spiritual sustenance, but also reflects the rich regional culture and folk religious beliefs.

\section{Classifications and Characters in Xiaoyi Shadow Play}

Xiaoyi shadow play is divided into two branches, namely Light Shadows on Papered Window and Wanwan Shadow Play. The former is a native shadow play while the latter is imported from Shaanxi in the late Qing dynasty. The play screen is a window covered with white linen paper. Sesame oil 
lamps behind shadow figures onto the papered window, so it is also called "Lamp Shadows" or "Light Shadows on Papered Windows" in folk. The major musical instrument is the small Suona, which is also known as the "Xiaoyi blowing". It is one of the earliest blowing arts in the folk of China. Xiaoyi Blowing Window Shadows is not only the representative of Xiaoyi local folk art, but also the representative of Chinese traditional shadow shows. It occupies an important position in the history of the China shadow shows. The show plays mainly cover supernatural subjects. Most of the stories are come from "Feng Shen Yan Yi", and have been integrated with local folk paper-cut art, puppetry art, as well as the local folk culture. The carved characters have outstanding personalities and fixed images, even the horses for characters are also fixed. For example, Huang Tianhua has Jade Kirin while Jiang Ziya has Sibuxiang (neither fish nor fowl) (figure 1). The early shadow workers carved figures on sheepskin, and the height of persons is two feet. In Qing Dynasty, the shapes of persons did not change, but the material of shadows became cowhide, and the faces of persons become more realistic, the height of persons became one foot and a half. The shadow figures have casual dress and rough lines. Usually one shadow figure is consisted of nine block structure. It has already formed the complete shadow figures form, and shows the charm like Han Dynasty stone relief.

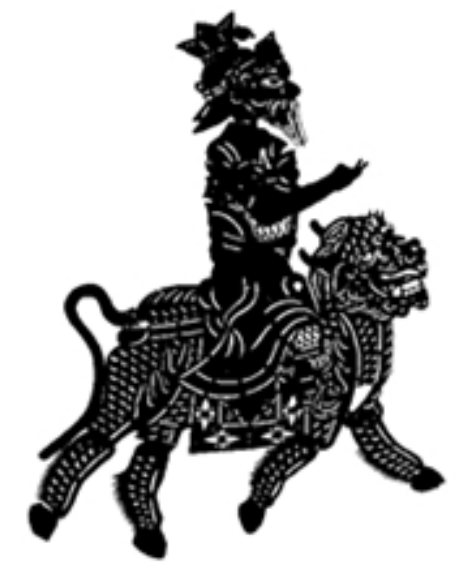

Figure 1 Light Shadows on Papered Window Jiang Ziya[4]

Originate from: Hou Pilie. An Introduction of Xiaoyi's Shadow Play in China [M].Shanxi Education Press, pp. 48。

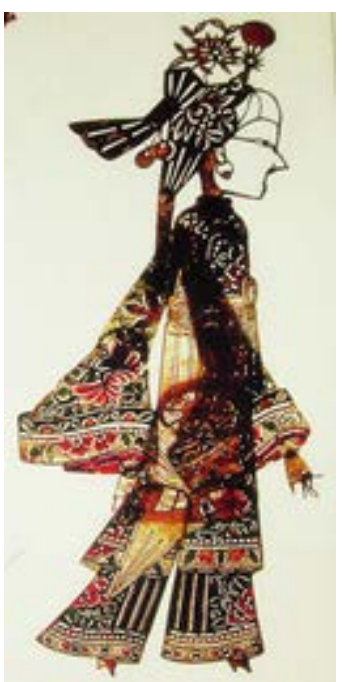

Figure 2 Wanwan Shadow Play Rich Female

Originate from: Hou Pilie. An Introduction of Xiaoyi's Shadow Play in China [M].

Shanxi Education Press, pp. 125.

Another shadow play in Shanxi is "Wanwan Shadow Play" imported from Shaanxi. Wanwan is commonly known as "Gu Gu" (a kind of bowl in China). It is also called "Chinese drama" or "Shi Qiang". It originated from the folk art of "rap" in Guanzhong area. Different from the blowing paper window shadows, Wanwan relies on light shadows on screened windows. It is called "Wanwan" because the major musical instrument of this play is a copper percussion with $6 \mathrm{~cm}$ diameter and 
looks like a small bowl. Other musical instruments include Huhu, Erxuan, Yueqin, Copper Bell, etc. Compared with the leather cavity, songs in Wanwan is more elegant and gentle. The themes are mostly historical stories, or folk tales on separation and union. Wanwan comes from Shaanxi, so its modeling characteristics have a lot of similarities with Shaanxi shadow play. Especially for the face design, the headdress of Wanwan has more decorations. Carving techniques are also delicate and exquisite. The models of figures are very strictly made and decorated. Meticulous carving techniques and stylized carving patterns can be found. The shadow figures in Wanwan are relatively small in size, the height of them are usually nine to ten inches. Facial features of figures include high forehead, straight nose and small mouth-- "curved eyebrows, narrow eyes, small mouth looks like a cherry" (Figure 2). The characteristics of persons are often featured as horizon or erect eyebrows.

\section{Analysis of the Art Features of Xiaoyi Shadow Play}

First of all, the plane style of shadow play carving is a common feature of many local shadow plays. While performing, the scene layout of shadow play show is the left -right and up-down segmentation instead of three-dimensional segmentation. The design and manufacture of the patterns of Xiaoyi shadow play is based on the people's beliefs in reality. At the same time, it abandons the naturalism imitation. The characters' face of shadow play generally uses the front and side view with fifty percent while the headdress and dress uses the half side with seventy percent, namely " fifty percent face and seventy percent appearance". In addition, the chair style and table style in the shadow play scene are various. Its delicate carving adopts "seventy percent appearance", which makes people comfortable sitting on the chair. (Figure 3)

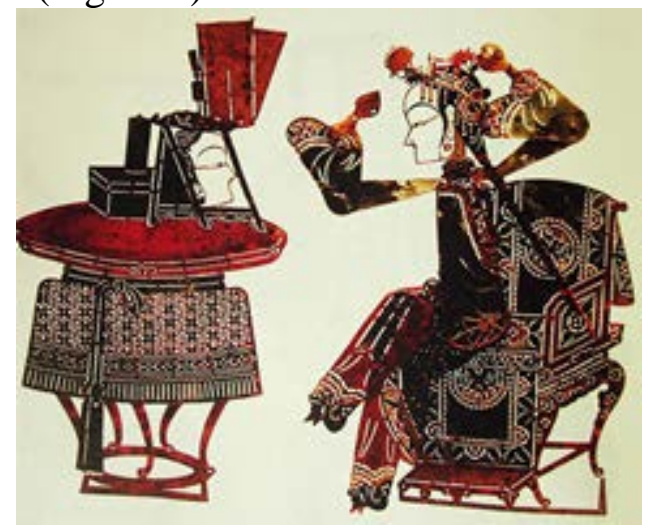

Figure 3 Lady's Dressing Table

Originate from: Hou Pilie. An Introduction of Xiaoyi's Shadow Play in China [M]. Shanxi Education Press, pp. 142.

In addition, the abstract patterns of shadow play and its exaggerated style is a common feature of the shadow play. It is based on the broad aesthetic habits. And it breaks traditional principles of painting sculpture and greatly exaggerates the characters in reality, which makes the art vivid. In early period, most of Xiaoyi shadow play has myth themes in order to enrich the story and renders the atmosphere. For instance, ghosts, scorpion, pig and other exaggerated facial design. The various linear combination and bold color use make the characteristics incisive and vivid.

Furthermore, the harmony of colors and the comparison of complexity and simplicity are also important. The color of the patterns can enrich the appearance of the shadow play. Shadow play color is affected by the folk "five colors". The traditional five primary colors are red, yellow, green, black and white. These colors also occur in the shadow play. After the folk artists' serious and special processing, the color of shadow play is based on the film character and Chinese aesthetic habits. For instance, the red face of Guan Gong represents bravery and integrity; the black face of Bao Zheng represents justice. The shadow play follows the principle of outer complexity and inner simplicity. The outer lines of the figures are generally simple and succinct while the inner lines are more complicated. But both of them show the unity, harmony, rhythm, radiation and cyclotron, which reflect a pleasing decoration and order. [5] 


\section{The Formal Beauty of the Patterns of Xiaoyi Shadow Play}

Xiaoyi shadow play has a unique artistic style, which embodies the common people's love of life and longing for the good things. People's perceptual sense of the outside world is closely related to the designers and the users' living environment, which is the embodiment of their cultural beliefs. Shadow design is always based on real life. For instance, some people like fairy tales in which the dress and the appearance are in common. Graphic styles, rich lines and diversified patterns make the images in reality be refined and summarized, so as to enhance the decorative effect and make it full of charm.

The decorative patterns of shadow play are both changeable and unified. All kinds of contradictions finally keep balanced and achieve harmony. "Change" is to find out the difference, such as stress, length and thickness of the lines and flexible changes. "Unity" is about the relationship between the whole and the coordination. The pattern and color combinations have the same or similar features. Shadow play mainly has two expression ways, incised carving and outside carving. Sometimes the two approaches are combined. The lines of incised carving are generally short and thin, so that the internal and external lines would be harmonious. The outside carving generally shapes the outside lines. The male character and the female character mainly adopt this face design. The combination of both incised carving and outside carving is more rich and diverse. In the decorative pattern design, the excellent usage of comparison helps to enhance the contents of the theme. Either comparison or harmony makes people comfortable and creates a harmonious and peaceful atmosphere. It is an important means to achieve change and unity.

The decorative patterns of shadow play show artistic conception. Ranging from primitive and simple geometric patterns in the early period to today's diverse patterns, we can see a long development process of the patterns. Our pattern design has a long history. During this processing, the continuous absorption of outstanding cultural essence and the inheritance of the traditional culture help to form the brilliant modern culture patterns. In addition to the external formal beauty, the artistic beauty of the patterns is also shown. The pattern styles of Xiaoyi shadow play are quaint and beautiful, elegant and refined. Based on the formal beauty, it reflects the artistic beauty.

\section{The Cultural Connotation and Functional Significance of Xiaoyi Shadow Play}

The traditional Chinese world outlook is "Harmony of Heaven and Man". It idolizes the nature which creates everything and focuses on people's inner experience. The shadow patterns are the deep insights on the nature and people's attitudes towards the world. The shadow play is influenced by local folk culture and folk beliefs; therefore, its style and expression form is abundant. With the development of history and the communication and integration between nations, the ancestors of human beings not only well preserve traditional culture, but also absorb foreign culture, making the design more brilliant. The patterns of Xiaoyi shadow play with distinct geographical and cultural characteristics originate from people simple life and have been improved in practice and generate a type of traditional folk art. The pattern styles of Xiaoyi shadow play are diverse, which is the embodiment of Chinese traditional culture and the spiritual world.

The survival value of shadow play determines its survival way. In the past, the shadow play was used for praying and asking god for help. It was performed in singing congregation, restaurant, teahouse, etc. With the development of society, due to the changes of people's living habits and the popularity of new art forms, the art of traditional shadow play has gradually began to decline. Shadow play art reforms and innovates in its repertoire, performance and marketing, which makes the old rebirth, like a blooming new tree. The story themes of the shadow play is rich, such as appreciating the good and punishing the evil, singing merits and praising virtues, and retributing for sin, etc. The shadow play helps to discipline us that we should praise virtues and abandon sins. These contents are not only the embodiment of Confucian ethics, but also maintain our social order to some extent.

Xiaoyi shadow play is an important form of folk art, especially 皮腔纸窗影, which is representative of the ancient Chinese shadow play and of great importance in cultural value and research. However, the art of shadow play is in the recession nowadays. In modern design, the 
application of the shadow patterns is also an effective way of inheritance and development, which enriches the modern design. Drawing nutrients from the shadow play patterns with traditional design and being aided by modern design help to integrate modern design philosophy into people's daily life, giving it a new art form and a better development.

\section{References}

[1] An Introduction of Xiaoyi. Haichao Press. June, 1992.

[2] Chu Zhihui. (2010). The Art of Xiaoyi Shadow Play and Its Development [J]. Inheritance \& Innovation, 12, 148.

[3] Chen Zhifo. (1930). ABC Patterns [M]. ABC Series Press, pp. 19.

[4] Hou Pilie. An Introduction of Xiaoyi's Shadow Play in China [M]. Shanxi Education Press, pp. 48, 125,142 .

[5] Wu Limin. (2005). Form Language Feature of Shadow Play in Xiaoyi [J]. Art \& Design, 3, 65. 